\title{
Televisão e espaço de revisitação: a formação de uma memória teleafetiva
}

\section{Mario Abel Bressan Junior}

Doutor; Universidade do Sul de Santa Catarina, Tubarão, SC, Brasil marioabelbj@gmail.com

\section{Resumo}

Este estudo objetiva analisar a televisão como espaço de revisitação social para a formação de uma memória teleafetiva do telespectador. Analisa o Canal Viva, que consiste numa programação composta por reprises. Como metodologia aplicada, utilizamos a Análise de Conteúdo de Laurence Bardin, a qual estabelece a investigação sobre os sentidos semânticos dos comentários dos telespectadores publicados no site de rede social Twitter. Os resultados mostraram que, além de afetiva, há uma memória teleafetiva, resultante dos efeitos emocionais advindos com a televisão, da socialização e dos afetos construídos com os grupos de referência. Há uma satisfação positiva em voltar ao passado por refazer um laço social com as reminiscências.

\section{Palavras-chave}

Televisão. Memória Teleafetiva. Memória Afetiva. Redes Sociais. Canal Viva.

\section{Introdução}

O objetivo deste artigo é analisar a função da televisão como elemento socializador e espaço para revisitação, capaz de formar uma memória teleafetiva no telespectador. Compreende parte - um recorte - da pesquisa desenvolvida por este autor em sua tese de doutorado defendida em 2017.

As recordações coletivas, bem como a identidade social dos indivíduos, traçam uma demarcação no espaço e tempo em que vivemos. Entender a memória é essencial para as diversas áreas em que a sociedade participa, pois, cada vez mais, percebe-se a volta de elementos do passado, configurando um presente nostálgico, composto por lembranças e 
memórias, seja na moda, na arquitetura, no design. É possível constatar esse movimento, podendo esse ser notado nos objetos de decoração e produtos da "linha retrô".

Há um indício, nesta conjuntura, de que é preciso olhar para este universo e observar que tipo de memória se estabelece nesta relação, se afetiva, racional, temporal ou outra manifestação sociocultural. A memória, como observa Huyssen (2000), é um dos fenômenos culturais e políticos que vem ganhando destaque nas sociedades ocidentais. Esse movimento "[...] caracteriza uma volta ao passado que contrasta totalmente com o privilégio dado ao futuro, que tanto caracterizou as primeiras décadas da modernidade do século XX," (HUYSSEN, 2000, p. 9).

Huyssen (2000) lembra que a memória da sociedade é acordada no corpo social dos valores, crenças, instituições e rituais. Os museus, memoriais e monumentos, por exemplo, formam memórias públicas. O recordar é que nos liga ao passado e a forma como rememoramos define como estamos no presente. "Como indivíduos e sociedades, precisamos do passado para construir e ancorar identidades e alimentar uma visão do futuro [...]". (HUYSSEN, 2000, p. 67).

É desta necessidade de compreender a relação da memória que este artigo se justifica. Na televisão, especificamente no Canal Viva, o que se vê são arquivos sendo exibidos tempos depois, evocando uma memória que, para nós, é afetiva. Há um prazer ao (re)assistir um programa. Se a recordação é um dos elementos que explicam como vivemos o presente, como dito por Huyssen (2000), é preciso olhar para o atual telespectador e tentar perceber a importância que este tipo de programação possa ter na construção da sua identidade bem como na sua relação com o mundo.

A televisão, como observa Ferrés (1998), consiste num instrumento de transmissão de ideias, de sentimentos e de comportamentos e que influenciam no processo de socialização e construção do ser humano, por evocar mais emoção do que reflexão e por atingir o inconsciente. Por isso, para o autor, são as emoções que condicionam as percepções da realidade. "Sabe-se que as crianças pobres tendem a estimar ou lembrar as moedas como maiores do que são na realidade, em comparação com as crianças ricas. Seu próprio desejo modifica a percepção." (FERRÉS, 1998, p. 30).

Estudar esta relação afetiva e emocional da memória dos telespectadores nos interessa para compreendermos como isso pode alterar um comportamento e provocar reações a partir de uma programação reexibida tempos depois. 
Mesmo vivendo numa fase pós-televisão, na qual estamos diante da conectividade e convergência no meio televisivo, há uma memória social, coletiva e afetiva do telespectador (BRESSAN JÚNIOR, 2017). Por isso, este artigo procura responder como acorre a formação da memória teleafetiva da audiência ao revisitar espaços coletivos com a televisão.

Como objeto de estudo analisamos o Canal Viva, que em maio de 2018 completa oito anos no ar. Estreou no dia 18 de maio de 2010. A programação, na sua maioria, consiste de produtos que pertencem ao arquivo da Rede Globo de Televisão. Essa grade é formada por telenovelas, programas de humor e musicais, seriados, filmes antigos e algumas produções do próprio canal.

Como procedimentos metodológicos, utilizamos a Análise de Conteúdo, de Laurence Bardin (2011). Com ela é possível classificar e categorizar as mensagens. Definimos por estudar os sentidos semânticos descritos, avaliando verbos, adjetivos e expressões, que direcionam um entendimento sobre o que pensa, faz e recorda o público que assistiu no Canal Viva, em 2016, a telenovela Laços de Família.

Este artigo contribui para futuras pesquisas em relação a televisão e memória, como também para profissionais, estudantes e leitores que objetivam estudar um pouco mais sobre as recordações e as afetividades provocadas pela programação televisiva.

\section{Memória e memória teleafetiva}

A memória é considerada um espaço onde guardamos as informações que adquirimos ao longo da vida, um lugar de armazenamento. As lembranças surgem porque estão inseridas neste ambiente. São emitidas cada vez que a memória é chamada, ou seja, só é possível "chamar" as recordações porque estão dentro de uma memória (IZQUIERDO, 2016).

Além de ser evocada, a memória exerce um papel sociocultural relevante, na medida em que traz contextos significativos para a compreensão de como vivem e atuam as sociedades.

Izquierdo (2011) destaca que a memória consiste na “[...] aquisição, formação, conservação e evocação de informações." (IZQUIERDO, 2011, p. 11). 0 sujeito adquire porque aprende e, por isso, só registra o que foi aprendido. É a partir deste registro que as 
evocações aparecem. Para Izquierdo (2011, p. 11) a “[...] evocação é também chamada de recordação, lembrança, recuperação. Só lembramos aquilo que gravamos [...]“.

No entanto, este arquivamento também acontece em função do contato social e coletivo que possuímos. Aprendemos e guardamos reminiscências pelo contato com outras pessoas e com os grupos de referências.

Importante pensar neste aspecto, visto que a memória vem a trazer esta reconstrução sobre uma lembrança, seja através de amigos, familiares ou até mesmo revisitando uma cidade, um conhecido ou antigo local de trabalho. Todos trarão recordações que serão otimizadas diante da interferência do hoje, mas que houve uma interação social (BRESSAN JÚNIOR, 2017, 2018).

A visita aos lugares faz relembrar fatos que podem ser pessoais, únicos. Todavia, estão ligados também a outros sujeitos, pelo mesmo ambiente e espaço provocador da lembrança. A coletividade se dá por este mesmo ponto.

Assim que evocamos juntos diversas circunstâncias de que cada um de nós lembramos (e que não são as mesmas, embora relacionadas aos mesmos eventos), conseguimos pensar, nos recordar em comum, os fatos passados assumem importância maior e acreditamos revivê-los com maior intensidade, porque não estamos mais sós ao representá-los para nós. Não os vemos agora como os víamos outrora, quando ao mesmo tempo olhávamos com os nossos olhos e com os olhos de um outro. (HALBWACHS, 2003, p. 29-30).

Como diz Halbwachs (2003), as nossas memórias continuam coletivas e são acionadas por outros, mesmo em situações e eventos (como ele gosta de referir), em que estivemos sós. Para ele, o sujeito nunca está sozinho. "Não é preciso que outros estejam presentes, materialmente distintos de nós, porque sempre levamos conosco e em nós certa quantidade de pessoas que não se confundem." (HALBWACHS, 2003, p. 30) .

A memória só parece ser unicamente um fenômeno individual, acrescenta Pollak (1992). Mesmo relativamente íntima e da própria pessoa, é constituída, ainda, por ordem coletiva, perpassa por flutuações e alterações, mas em algumas circunstâncias é infindável . "Se destacarmos essa característica flutuante e mutável da memória, tanto individual quanto coletiva, devemos lembrar também que na maioria das memórias existem marcos ou pontos relativamente invariantes, imutáveis." (POLLAK, 1992, p. 201).

É importante verificar, contudo, que há elementos que podem contribuir para a formação de uma rememoração, em virtude dessa relação coletiva. Para Pollak (1992), os acontecimentos vividos por cada indivíduo irão formalizar uma constituição individual da 
memória, justamente com os "vividos por tabela", ou seja, o que para ele correspondem aos acontecimentos desencadeados pelos grupos a que as pessoas pertencem.

São acontecimentos dos quais a pessoa nem sempre participou, mas que, no imaginário, tomaram tamanho relevo que, no fim das contas, é quase impossível que ela consiga saber se participou ou não. Se formos mais longe, a esses acontecimentos vividos por tabela vêm se juntar todos os eventos que não se situam dentro do espaço-tempo de uma pessoa ou de um grupo. É perfeitamente possível que, por meio da socialização política, ou da socialização histórica, ocorra um fenômeno de projeção ou de identificação com determinado passado, tão forte que podemos falar numa memória quase que herdada. (POLLAK, 1992, p. 201).

Além dos acontecimentos, Pollak (1992) explica outros fatores que organizam as memórias dos sujeitos. Para ele, nos deparamos constantemente com personagens e lugares que proporcionam um reencontro com o passado. Os personagens podem ser encontrados no dia-a-dia, vistos também por tabelas e os que não pertencem necessariamente ao espaçotempo do indivíduo. Na ordem dos grupos de referências, amigos e familiares estariam classificados como os do cotidiano. Um parente pode fazer uma ação e evocar uma lembrança. Os identificados por tabela e os que não fazem parte do mesmo tempo e espaço podem ser as pessoas e figuras que vimos em livros, na televisão, ou que encontramos nas ruas. De certa forma, concordamos que são mecanismos que possibilitam rememorações de algo.

Do mesmo modo, os lugares. Como exposto anteriormente, Halbwachs (2003) discute os locais que evocam uma lembrança. Pollak (1992) corrobora essa ideia e explica que há lugares onde estamos diretamente ligados e, por isso, trazem reminiscências. Pode ser algo pessoal ou coletivo, independente de uma ordem cronológica. Uma ação vivida na infância, um passeio, uma visita, qualquer zona ou sítio que possa rememorar algo.

Concordamos, perante esses aspectos, que a leitura de um livro, ou um programa de televisão, também pode ser considerada local de evocação.

Esses três critérios, acontecimentos, personagens e lugares, conhecidos direta ou indiretamente, podem obviamente dizer respeito a acontecimentos, personagens e lugares reais, empiricamente fundados em fatos concretos [, e que podem, nesses casos, ocorrer transferências e projeções]. (POLLAK, 1992, p. 202). 
São projeções no sentido de que nem sempre vivemos o que lembramos. São fatos passados por gerações ou aprendidos.

A presença do indivíduo em um grupo não necessariamente deve ocorrer fisicamente, mas na forma adotada para retomar às formas de pensamentos e vivências proporcionadas pelo grupo. "Para confirmar ou recordar uma lembrança, não são necessários testemunhos no sentido literal da palavra, ou seja, indivíduos presentes sob uma forma material e sensível." (HALBWACHS, 2003, p. 31). Esta participação coletiva vai além da presença física, pois está ligada a outras formas de "estar junto". 0 sujeito pode partilhar de momentos comuns ao revisitar uma cidade que ele conhececom familiares. No momento deste retorno, ele está sozinho. Contudo, a primeira vez em que ele foi até lá, havia outras pessoas consigo.

Da mesma forma em que ao viajar sem a presença de uma companhia a um país desconhecido, mesmo só, sem ninguém próximo para conversar, outros indivíduos estão ali, construindo juntos os pensamentos e as lembranças sobre aquele lugar.

0 mesmo podemos relacionar com o hábito de assistir TV. A programação apresentada por ela faz com que as pessoas tenham contato com um outro grupo de referência, neste caso as pessoas, as histórias e todos os conteúdos inseridos nela.

Nessa perspectiva, a televisão consiste em um dispositivo que produz imagens e lembranças constantes aos telespectadores. Ao reprisar um programa, este expõe elementos que serão percebidos e, com isso, uma recordação será impulsionada. 0 arquivo televisivo carrega consigo esta qualidade de rememorar um tempo passado.

Quando essas reminiscências são compostas por sentimentos, temos uma memória que, além de afetiva, passa a ser teleafetiva, faz vibrar ainda mais o pensamento, visto que a TV envolve os indivíduos em experiências individuais e coletivas, de forma igualitária, como definido por Wolton (1996).

Para Wolton (1996), a TV de massa adquire duas funções parcialmente distintas, a de sustentar o laço social na sociedade, que é padronizada e, ao mesmo tempo, conceder este laço num contexto que aparece cada vez mais contraditório. Por isso ela é uma atividade transversal e que religa indivíduos a uma mesma bagagem, comprovando sua força.

Para Wolton (1996) , a televisão serve como instrumento de comunicação entre indivíduos pelo fato de pautar suas conversas sobre o que se vê na TV e não ao que se assiste. Por isso, ela é um objeto que possibilita a conversação, dentro e fora de casa, sobre o 
conteúdo exibido. "Nisso é que ela é um laço social indispensável numa sociedade onde os indivíduos ficam frequentemente isolados e, às vezes, solitários." (WOLTON, 1996, p. 16).

No entanto, acreditamos que o laço social atual, com a participação dos telespectadores em redes sociais, passa a ser não anônimo. A participação em rede permite saber quem e quantas são as conversas a respeito de determinado programa. No Brasil, o telespectador vem se "[...] tornando cada vez mais multitela: 88\% dos internautas assistem à TV e navegam na internet ao mesmo tempo por smartphone (65\%), computador $(28 \%)$ ou tablet (8\%)." (LOPES; GRECO, 2016, p. 139).

O déjà vu na televisão possibilita laços constantes. Quem assistiu a uma programação há tempos está inserido em um laço social. Assim, quando revê a cena, além do laço formado naquela época, outros são constituídos, a partir de uma memória resgatada.

A Figura abaixo ilustra o laço social sendo reconstruído através dos impulsos das recordações.

Figura 1 - Laço social reconstruído com as recordações

\section{Laço social \\ na TV aberta}

Teia Invisível

\section{Laço social da TV \\ nas redes sociais}

\section{Visível- Não anônimo}

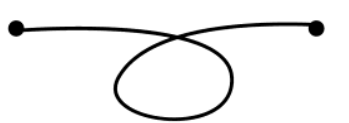

Fonte: Bressan Júnior (2017).

Laço social dos telespectadores no canal viva

\section{- Com a memória teleafetiva}

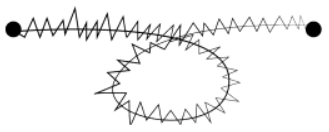

Chamamos de memória teleafetiva essa que é reconquistada, reformulando novamente uma experiência, que é reconstruída por um tipo de emoção e de afeto. Como explicado por Halbwachs (2003), em alguns momentos, é preciso fazer dos depoimentos exteriores uma espécie de semente de rememoração para que possa fazer surgir as lembranças. A TV executa este papel. Consiste em um dos elementos externos que auxiliam na volta ao passado (BRESSAN JÚNIOR, 2017).

Esta memória teleafetiva é a responsável por recuperar e reformular reminiscências reconstituídas a partir das imagens exibidas na televisão e pelos afetos em torno das vibrações provocadas por ela. Além de socializadora (FERRÉS, 1998), de Laço Social (WOLTON, 1996), a TV pode ser um desses "lugares" (HALBWACHS, 2003) que revisitamos e que são percebidos pelas nossas memórias. 
Difere-se da memória afetiva por trazer pulsões geradas a partir da visualização das imagens televisivas, provocadas pelos efeitos emocionais durante o ato de (re)assistir. A teleafetividade da memória, neste caso, é resultado do laço social reformulado pelas recordações.

Ilustramos, com a imagem a seguir, um telespectador diante de uma (re)exibição . As letras correspondem aos objetos percebidos e, do outro lado, já no cérebro, os mesmos elementos, mas com vibração proporcionada pela memória teleafetiva. Os números representam outras lembranças e recordações, impulsionadas por emoções vividas em uma época.

Figura 2 - Vibração com a memória teleafetiva

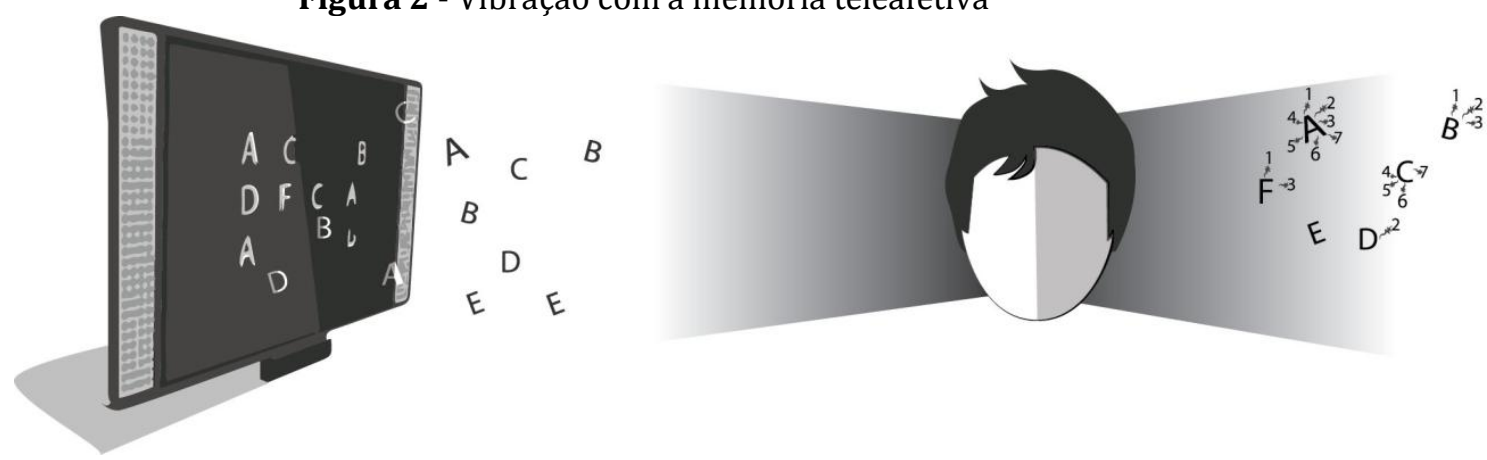

Fonte: Bressan Júnior (2017).

A televisão proporciona esta relação teleafetiva por ser um dispositivo que rememora, recria reminiscências e que esteve e está presente no dia a dia do telespectador. Os afetos estão presentes na experiência televisiva por ser a TV um meio que socializa os indivíduos, pertence a uma coletividade e provoca emoções com o que é assistido. Sentimentos de amor, raiva, irritação e saudade podem ser sentidos com as mensagens audiovisuais (BRESSAN JÚNIOR, 2017).

\section{Memória, emoção e afeto}

Duas grandes contribuições para a compreensão da função das emoções em seres humanos ocorreram com as publicações: A expressão das emoções no homem e nos animais, de Charles Darwin, e $O$ que é uma emoção?, de William James, em 1872 e em 1884, respectivamente. 
Darwin (1965' apud CAIXETA, 2006) concluiu que as expressões emocionais são padrões próprios dos indivíduos, padrões de ações vestigiais, ou seja, vêm de características já demonstradas em outros animais, como, por exemplo, o fato de mostrar os dentes quando com raiva é bem semelhante ao cachorro rosnando quando enraivecido ou ameaçado. Outro ponto das conclusões darwinianas é que possuímos um conjunto básico e limitado de emoções, tais como: raiva, tristeza, medo e surpresa (CAIXETA, 2006).

Quando falamos sobre a ação de partilhar lembranças com outras pessoas, lembramo-nos do que Halbwachs (2003) nos diz sobre a constituição da memória coletiva. Nossas experiências passam a exercer um sentido emocional que deve ser observado e que passa a impactar o sentido de nossa existência.

"O homem está afetivamente presente no mundo [...]", diz Le Breton (2009, p. 111). 0 simples fato de existir provoca um contínuo fluxo de sentimentos que podem ser mais ou menos vivos e pode mudar de acordo com as circunstâncias. Para o autor, "O gozo do mundo é uma emoção que cada situação renova de acordo com suas próprias cores [...]“(LE BRETON, 2009, p. 111), e mesmo a ação de pensar não escapa a seleções. Como vimos, o pensamento é uma atividade que faz parte da memória, traz elementos correspondentes às recordações. Assim, é importante salientar que no ato de lembrar também vem consigo questões emocionais, visto que não há como separar pensamento e afetividade.

Como afirma Le Breton (2009), o sujeito não está inserido no mundo como um objeto e com sentimentos passageiros, mas é sempre submetido às influências dos acontecimentos e sendo tocado por eles, em virtude das suas ações e relações com os outros. “Mesmo as decisões mais racionadas ou mais 'frias' envolvem afetividade. São processos embasados em valores, significados, expectativas, etc. Seu processamento envolve sentimentos, o que diferencia o homem do computador." (LE BRETON, 2009, p. 112).

São os afetos que simbolizam a permanência, a relação do homem com o mundo e a sua intimidade inserida nos acontecimentos do quotidiano, explica Le Breton (2009). Temos sempre uma apropriação de afeto sobre os objetos que nos cercam e que é duradoura, independentemente do tempo. "A emoção é a própria propagação de um acontecimento passado, presente ou vindouro, real ou imaginário, na relação do indivíduo com o mundo “. (LE BRETON, 2009, p. 113). Exposta em momento provisório, é originada de um fato, no

\footnotetext{
${ }^{1}$ DARWIN, C. The expression of de emotions in man and animals. Chicago: Chicago University Press, 1965. Apud Caixeta
} (2006). 
qual o "[...] sentimento se cristaliza com uma intensidade particular: alegria, cólera, desejo, surpresa ou medo." (LE BRETON, 2009, p. 113).

Le Breton (2009), no entanto, esclarece que os sentimentos de amor e raiva estão mais presos ao tempo, arraigados, e se mostram mais integrados às práticas da vida. Mais que todos, refletem este preenchimento no dia-a-dia em função da emoção vivenciada. Para ele, a emoção é situada no tempo por algum sentimento, dissolvendo-se em momentos que são interligados.

São os objetos os responsáveis em oferecermos algum tipo de afeto. Sentimento e emoção nascem em função da relação que possam ter sobre algo definido por nós e das circunstâncias de nosso movimento. São baseadas a partir de "Um repertório cultural que distingue as diferentes camadas da afetividade, misturando as relações sociais e os valores culturais ativados pelos sentidos." (LE BRETON, 2009, p. 114).

As emoções seguem as lógicas pessoais e sociais de um sujeito que pensa e agrupa, de acordo com Le Breton (2009), traços em sua memória, impregnada do seu olhar sobre os outros e sobre o mundo. Então,

As emoções que nos acometem e a maneira como elas repercutem sobre nós têm origem em normas coletivas implícitas, ou, no mais das vezes, em orientações de comportamento que cada um exprime de acordo com seu estilo, de acordo com sua apropriação pessoal da cultura e dos valores circundantes. São formas organizadas da existência, identificáveis no seio de um mesmo grupo, porque elas provêm de uma simbólica social, embora elas se traduzam de acordo com as circunstâncias e com as singularidades individuais. (LE BRETON, 2009, p. 117).

Assim, mesmo apresentando emoções individuais, essas aparecem em função dos contextos sociais e simbólicos. 0 olhar sobre o mundo é ativado por nossas apropriações pessoais e culturais, mas há interferências das relações coletivas.

A afetividade, segundo Le Breton (2009), consiste na mistura de acontecimentos significativos, tanto de ordem pessoal, quanto coletiva, e que colocamos em prática, originando um sistema de valores e interpretando as situações conforme referências morais construídas por nós. Exemplo disso são as superstições, cuja crença ativa as emoções, como o horóscopo, que diz que a pessoa terá um dia alegre, ou que, ao cruzar com um gato preto, terá um dia angustiante. Neste sentido, Le Breton (2009) esclarece que a emoção é indicada pelo grupo que dá importância a isso, como também é a definição por como vive o indivíduo e como este existe perante o mundo. 


\section{Procedimento metodológico}

O artigo possui como campo de análise a internet, por meio das menções dos termos publicados no Twitter sobre a telenovela Laços de Família, (re)exibida no Canal Viva em 2016.

A internet, explicam Fragoso, Recuero e Amaral (2013), pode ser tanto objeto (o que é estudado), local (espaço onde é realizada a investigação) e instrumento de pesquisa (mecanismo para coleta de dados). Dessa forma, temos essa como campo para busca de elementos e informações para a concepção da análise. Este procedimento metodológico possui amparo em ações e conceitos de transmidiação, que vem crescendo muito no Brasil.

Vem aumentando a participação dos brasileiros na rede. Em 2015, Lopes e Greco (2016) destacam que a telenovela Império (Globo) obteve 18,9 milhões de impressões no Twitter, 560 mil tweets e 133 mil autores participando e comentando sobre a narrativa. "Durante cinco semanas, essa ficção permaneceu como assunto mais comentado na internet." (LOPES; GRECO, 2016, p. 75).

Na TV fechada, do mesmo modo, vem chamando a atenção do público que se divide entre a TV e as redes sociais. No Viva, por exemplo, com a telenovela Por Amor, (re)exibida em 2017, a hashtag \#PorAmorNoVIVA esteve diversas vezes no Trending Topics do Twitter (SECCO, 2017).

Diante desses dados, justificamos o uso da ferramenta Twitter para campo de investigação, visto que, conforme descrito por Lopes e Greco (2016), é considerável e notável a importância desta ferramenta como espaço de compartilhamento de conteúdo e como espaço para "conversas" sobre ficção.

Baseamos esta escolha também, no que Fechine (2014) chama de "sofá estendido", visto que são classificações de conversas interpessoais que acontecem no espaço off-line e que agora migram para o on-line. São temas que estão presentes no laço social, no dia a dia das pessoas e pautam discussões.

Como metodologia, aplicamos a Análise de Conteúdo de Laurence Bardin (2011), visto estarmos diante de manifestações discursivas a respeito do objeto de estudo. Para a autora, a análise de conteúdo consiste em mostrar indicadores, podendo ser quantitativos ou qualitativos, o que permite o conhecimento das condições de produção e recepção das mensagens. 0 primeiro indicativo consiste na exibição quantitativa dos números de 
publicações, para que, a partir disso e após a leitura flutuante dos comentários, possamos construir as categorias de análise.

Bardin (2011) defende que os critérios para categorização e agrupamento dos dados podem ser semânticos (categorias temáticas), sintáticos (verbos, adjetivos), léxicos (sentido das palavras, sinônimos) e expressivos (categorias que expressam conflitos diversos da linguagem). A importância de classificar estes elementos se dá, segundo a autora, pela proximidade que possam ter. Por isso, a classificação permite ver partes comuns entre eles.

Optamos pela categorização semântica, no sentido de estabelecer categorias temáticas e, a partir disso, estudá-las, conforme os elementos que aparecerão no discurso dos telespectadores ao comentar sobre a narrativa Laços de Família, a partir da data de estreia, 15 de fevereiro de 2016. Delimitamos a investigação na telenovela, por ser essa um forte produto cultural (WOLTON, 1996) e ocupar lugar de destaque na programação do canal Viva. São quatro produções (re)exibidas diariamente.

Coletamos os dados com o auxílio da ferramenta Grid Monitoramento, que permite inserir os termos pesquisados e obter a primeira classificação das postagens. 0 Grid é um software utilizado pela Universidade do Sul de Santa Catarina (UNISUL), local de trabalho deste pesquisador, que funciona como um monitor em sites de redes sociais e que permite a busca de termos chave no Twitter.

Como recorte, optamos por seis dias, ou seja, uma semana de exibição. As menções na rede social foram capturadas do primeiro ao sexto dia após a estreia. Isso em função de percebermos, com a leitura flutuante, uma expectativa maior dos telespectadores neste período, ao reviver as cenas de uma narrativa acompanhada tempos atrás. Preferimos capturar as falas nestes reencontros, proporcionadas pelo déjà vu, para ver o "redesenho", quadro de lembranças formado.

Outro ponto que justifica a escolha de seis dias é que "fecha" a semana de exibição de uma telenovela. Elas iniciam na segunda-feira e terminam no sábado. Culturalmente, temos este fluxo horizontal na programação televisiva.

A classificação e o tratamento dos dados ocorreram sempre na semana posterior à coleta realizada pela ferramenta Grid, que possibilitou exportar os dados para uma planilha de Excel, na qual foi possível ler todos os comentários e agrupá-los. Com a opção AutoFiltro, foi permitido separar o corpus em grupos. Dentre esses, identificamos os tweets que trouxeram algum tipo de lembrança. 
Para o termo, Laços de Família, foram coletados 926 tweets. Destes, 189 foram desconsiderados por não terem relação com a telenovela ou por se tratar de postagens realizadas por veículos de comunicação. Dos 737 comentários que restaram, somente 51 apresentaram recordações, os outros elogiavam a história, parabenizavam, criticavam ou anunciavam o início e fim do capítulo.

O intuito desta pesquisa é expor como a memória é acionada ao revisitar cenas da telenovela, por isso, o corpus para análise constituiu esta delimitação.

\section{Memória e espaço de revisitação em Laços de Família: traços de uma memória teleafetiva}

Em relação aos elementos que trouxeram algum tipo de recordação, observamos as expressões "gostava", "era chique" e "tornei fã" como conteúdo que direcionam alguma satisfação, mas que consistem em verbos conjugados no tempo passado, o que entendemos como referências de memórias advindas da telenovela Laços de Família. Para a análise, os twetts serão descritos na íntegra e em itálico, a partir desta seção, respeitando os sentidos semânticos descritos pelos telespectadores.

Lembro q gostava muito dessa personagem de Debora Secco nessa novela. \#LaçosDeFamilia

Na época de \#LacosDeFamilia era chique dirigir falando ao celular. \#LacosDeFamiliaNoVIVA

@nononono @gio_antonelli foi em \#LaçosDeFamilia que me tornei fã da Gio.Eu tinha 11 anos e tb fã da@cadieckmann MUSAS

Vimos um sujeito manifestar a lembrança pela sua preferência, ao dizer seu gosto pela atriz Deborah Secco; outro fez menção a um período em que se podia dirigir e falar ao celular ao mesmo tempo; e uma terceira pessoa estabeleceu um diálogo com um amigo ao marcar com “@” o perfil de outro usuário. Nesse, o sujeito lembrou que possuía 11 anos quando conheceu melhor as atrizes Giovana Antonelli e Carolina Dieckmann através da telenovela.

Os comentários acima expõem algumas das lembranças que o Canal Viva proporcionou. Percebemos que, mesmo constituindo uma atividade individual, há uma relação coletiva na memória. 0 fato de lembrar como era fã da atriz e que gostava de uma 
personagem confirma que há outras pessoas e grupos na constituição de memórias. Neste caso, o Canal Viva apresenta a função de socializar (WOLTON, 1996; FÉRRES, 1998) e impulsiona, com as reprises, recordações que são coletivas. Um dos sujeitos lembrou a idade, 11 anos, ao rever as personagens. Halbwachs (2003) diz que a memória é adquirida pela participação do indivíduo em grupos de referência. No ano 2000, quando a telenovela foi exibida pela primeira vez, esse telespectador pertencia a grupos de referências e a narrativa das 21 horas, transmitida pela Rede Globo, provavelmente, era um deles. Em 2016, quando ele assiste novamente "aquele grupo", as memórias aprendidas (IZQUIERDO, 2011) são recuperadas. Mesmo estando ele em outras comunidades, aquela de anos atrás é acionada. Consiste numa relação teleafetiva da memória, visto ser a TV este lugar de pulsões, que recria um laço social com a interferência do passado.

0 mesmo acontece com as lembranças de uma trilha sonora.

\section{\#LaçosDeFamília ótima trilha sonora, ótima nostalgia ??}

Sou muito apaixonado por essa música desde pequeno e não me aguento de emoção por voltar a novela. \#LaçosDeFamília [...]

Nestes comentários percebemos duas pessoas escrevendo sobre a emoção que sentem ao escutar as músicas de Laços de Família. O primeiro considera ótimas as canções e vem o sentimento nostálgico. 0 segundo se refere à paixão que sente pela música e que desperta emoção ao rever a telenovela.

Importante refletirmos sobre isso. São duas "falas" significativas, pois trazem questões emocionais fortes. Este "voltar a novela" confirma a programação do Viva como um lugar de revisitação (HALBWACHS, 2003). O telespectador volta no tempo ao estar diante do programa assistido. As trilhas sonoras das telenovelas podem ser estes "lugares", assim como as personagens da história e outros elementos que fazem o enredo. Nos comentários abaixo, percebemos as saudades de atores e atrizes e como as reminiscências podem levar a outros objetos, não só os que estamos assistindo no momento.

Que saudade que eu tava da Marly Bueno <3 \#LaçosDeFamília

Ihhh...Antony e Dona Nenê!!!!! Me deu uma saudade de verdades secretas!!!! \#Laçosdefamilia 
NÃo consigo lembrar a música de abertura de \#LaçosdeFamilia. Só me vem o "quando a luz dos olhos meus.." de Mulheres Apaixonada kkkk

A televisão aciona recordações. As memórias evocadas, quando diante da reexibição do Canal Viva, impulsionam para outras memórias. Isso consiste na força da TV como mecanismo de recuperação de reminiscências. Os dois comentários acima lembraram outras histórias através das imagens de Laços de Família. Um deles demonstra uma saudade da telenovela Verdades Secretas, exibida em 2015, no horário das 23 horas na Rede Globo. Nesse tweet, percebemos três narrativas. Antony era a personagem de Reynaldo Gianecchini e Dona Nenê foi interpretada por Marieta Severo em A Grande Família. Ambos os atores estão na obra de Manoel Carlos. Ele como Edu, e ela, Alma. O mesmo acontece com o "esquecimento" da música de Laços de Família. Mulheres Apaixonadas, também de Manoel Carlos, traz a personagem Helena, vivendo outro drama familiar. 0 trecho da canção "quando a luz dos olhos meus" foi lembrado e este consistia do tema de abertura daquela outra história. Essa "mistura" de lugares revisitados num mesmo instante acontece em função dos pensamentos associativos (FERRÉS, 1998) que as imagens proporcionam.

No que se refere à memória, Mulheres Apaixonadas e Verdades Secretas podem ser referências de boas histórias e emoções sentidas, considerando a lembrança delas. Ferrés (1998) explica que, num processo de transferência afetiva, há elementos positivos e negativos, tanto para coisas ou pessoas, e que isso ocorre em função dos sentimentos transportados.

\section{\#lacosdefamilia bate uma nostalgia louca}

Nossa, tá passando \#LaçosDeFamília, e que saudade ? Primo da Talitinha nesse tempo era só o filé ??

Eu estou só querendo a novela que marcou minha vida \#LacosDeFamilia e é no @canalviva as $23 h 45[$ [...]

Consideramos as saudades comentadas acima como positivas. Trouxe novamente a nostalgia, a lembrança de um tempo e de um período importante na vida de um dos telespectadores.

Há uma memória afetiva nesses tweets. A telenovela proporciona ao sujeito recordações que manifestam emoções. Como visto, Le Breton (2009) destaca que estamos emocionalmente ligados ao mundo de forma afetiva. Um dos comentários descreve uma 
"nostalgia louca". Ao analisarmos o sentido da expressão, percebemos algo que é bom de sentir. 0 ser nostálgico, por ser um elemento afetivo, faz bem. Consideramos uma emoção positiva, de acordo com as considerações de Le Breton (2009), pois as emoções carregam traços da memória de um indivíduo que pensa e agrupa as lógicas pessoais e sociais, com base no que vê sobre os outros e sobre o mundo. Consideramos a nostalgia um sentimento que surge desta relação das pessoas e com o que está ao seu redor. A televisão auxilia nessa construção.

No entanto, as lembranças evocadas por Laços de Família possuem alguns aspectos negativos. Assim como vimos comentários bons sobre personagens e atores, ao classificarmos, seguindo as concepções metodológicas, percebemos algumas recordações não positivas. As expressões "insuportável”, "fugiu de uma festa a fantasia”, "não suportava”, "compartimento do inferno" demostram isso.

\section{Lembrando o qt a Clara é insuportável \#laçosdefamilia}

Essa Ciça era uma personagem insuportável. Acabei de lembrar que não gostava dela. \#LaçosDeFamília

Ciça parece que fugiu de uma festa a fantasia dos anos 80. \#LaçosDeFamília

@canal.....nessa novela \#LaçosDeFamilia não suportava o personagem de Débora secco. ...chata e nojenta!!!

Muito quente no Rio de Janeiro...Lembrei da Branca: Que calor é esse?

Isso aqui tá parecendo o compartimento do inferno... \#LaçosDeFamília

Em todos esses tweets, os telespectadores descreveram lembranças ao assistir Laços de Família. Mesmo negativas, percebemos um sentimento descrito. Le Breton (2009) explica que o amor e a raiva estão mais propícios a enraizarem e a estar mais nas práticas vividas no dia a dia. São reflexos de emoções vivenciadas. A memória afetiva, nesse caso, é retomada por essas irritações e aversões, advindas da experiência televisiva, mesmo 16 anos depois. Ao reconstruir esses laços sociais, carregados de vibrações pelas emoções evocadas pela TV, tem-se a memória teleafetiva.

Afirmamos que a memória afetiva do telespectador pode ser composta por coisas que o agrada ou não, dependendo do conteúdo que a televisão mostra, e, com isso auxiliam nas 
evocações. Se a memória é aquisição, formação e evocação de informações (IZQUIERDO, 2011), a programação do Canal Viva rememora algo que foi adquirido tempos atrás.

A telenovela Laços de Família também trouxe recordações sobre algum momento triste na vida de alguns espectadores.

2000 foi um ano muito bom eu estava crescendo feliz numa escola que eu gostava e era bem aceita depois tudo virou merda! \#Lacosdefamilia

\#Lacosdefamilia me deixou deprimida kkkkkkkk poxa eu era feliz, saudável e nem era gorda.

\#laçosdefamilia eu que era triste descrente desse mundo... Amo

Gente chorei tanto com essa novela \#laçosdefamilia

Novamente percebemos memórias de afetos mais dolorosos e difíceis. Nas postagens, um telespectador descreve que, no ano 2000, era feliz, mas que agora, tempos depois, "tudo virou uma merda". Na "fala", presenciamos uma volta ao passado através da telenovela. Lembrou momentos naquele ano e que, para ele, eram felizes. Pareceu-nos um sentimento de perda, de insatisfação com tempo presente. 0 Canal Viva o fez retornar para aqueles momentos alegres.

Em outro tweet, vimos uma telespectadora "deprimida", porque lembrou que não era gorda durante a primeira exibição. Sorriu com a situação, através da expressão "kkkkkkkk", mas mostrou uma lembrança triste, que "era feliz" somente antes.

O terceiro comentário acima demonstrou que, mesmo amando a história, lembrou que "era triste e descrente desse mundo". Novamente outro sentimento negativo, mas mostra que, talvez, no presente, não sinta mais isso. Vimos a narrativa evidenciar uma descrença que ocorria durante a primeira exibição, mas que, ainda assim, existe um amor manifestado por ela. 0 quarto rememora que a telenovela o fez chorar muito. Justamente por ter como tema central a luta de uma mãe e de uma filha pela cura de um câncer.

Para Pollak (1992), a memória, mesmo flutuante e mutável, permanece invariante. Neste sentido, estes afetos mostrados nos comentários observados, mesmo individuais, estão inseridos num contexto coletivo e contribuem para a formalização de uma constituição individual da memória. Isso porque, de acordo com o autor (POLLAK, 1992), estamos constantemente diante de recordações "vividas por tabela", que auxiliam na composição da memória. A televisão pode ser um destes mecanismos que influenciam na 
constituição de memórias de forma indireta. 0 que aconteceu com o sujeito naquele ano (pegamos como exemplo o ano 2000, período em que Laços de Família foi exibida na Rede Globo), está indiretamente ligado à história que ele assistia. Em 2016, ao rever as cenas, lembrou-se de fatos de sua vida individual. Foi preciso a evocação externa para rememorar as afetividades.

Nas próximas postagens, identificamos lembranças gerais da audiência.

Sempre tive pena das lavadeiras/passadeiras/empregadas das novelas. Sempre vi minha mãe nelas. \#LaçosdeFamília

Nunca me chamaram de piranha, xatiada \#LaçosDeFamília

meu deus a mesa do almoço da novela durante o governo fhc eu tô passando mal \#laçosdefamília

Constituem comentários com abordagens negativas por encontrarmos palavras como "pena", "piranha", "xatiada" e "mal". Novamente, para dar esses sentidos e trazer as recordações, foi preciso que esses telespectadores revisitassem um local para acionar a memória. Estes lugares (HALBWACHS, 2003) servem para refazer, reconstruir e repensar o passado.

O mesmo relacionamos com o público do Canal Viva ao postar essas mensagens. Um deles lembrou a mãe, ao rever as empregadas na telenovela; outra se diz zangada por nunca terem a chamado de "piranha"; e o posterior se diz passar mal, ao ver a mesa do almoço na época em que Fernando Henrique Cardoso era presidente do Brasil.

Ao olhar tempos depois para as imagens, o público rememora com a consciência que ele possui nos tempos atuais. A televisão tem esta capacidade de trazer as recordações. As cenas (re)exibidas funcionam como uma espécie de fotografia a ser revelada. Assim como no processo de revelação fotográfica, à medida que o líquido químico vai penetrando no papel, a imagem surge de forma lenta até estar completa. As imagens que são reprisadas na televisão possuem um processo semelhante. Cada vez que as olhamos, nosso cérebro as reconhece e aos poucos se formalizam através de um "revelador", que, nesse caso, podem ser as percepções evocadas. Só evocamos porque aprendemos, destaca Izquierdo (2011), e nesse mecanismo consiste a ativação da memória.

Hora de assistir \#LaçosDeFamilia ???? Que saudade dessa novela! 
Matando a saudade... \#LaçosdeFamília?

Lembro q chegou uma hora q Edu e Helena lambiam até a lente da câmera, muita paixão, né? \#Laçosdefamilia

Olha! Nem lembrava que tinha @ShaniaTwain na novela \#LaçosDeFamília no @canalviva! \#shaniatwain

Nessa época a novela ainda era gravada nas próprias ruas do bairro, algo que hoje raramente acontece. \#LaçosDeFamília \#LaçosDeFamíliaNoViva

Os takes são tão longos que até lembro de Pantanal... \#LaçosDeFamíliaNoViva \#LaçosDeFamília

Vimos nestas postagens, novamente, a presença da saudade e de lembranças sobre a telenovela e até de outra, ao comparar a distribuição de tempo entre os capítulos. Há elementos na história que constituem as memórias afetivas. 0 amor entre os protagonistas pode ser um deles. 0 público deve ter ficado emocionado com o drama vivido entre eles e a filha com câncer. Como discutido em Ferrés (1998), as pessoas se movem por seus sentimentos e temores, e a televisão faz criar afetos e sentimentos de forma não consciente.

Percebemos que a telenovela cria circunstâncias, conforme explicado por Halbwachs (2003), para que as lembranças possam ser despertadas. Assim, ao rever o artista em cena, mesmo anos atrás, o público lembra-se dele e rememorações afetuosas poderão surgir.

Talvez naquele momento em que estavam vivendo as situações descritas, os telespectadores não demonstravam grande importância. Tornou-se grande na rememoração pela teleafetividade da memória.

o Canal Viva tem o indicativo de potencializar as memórias de um tempo, que foi significativo, vivido, mas que ficou para trás, voltando com a reexibição da programação. É pelo grupo de referência, diz Le Breton (2009), que a emoção é indicada. Laços de Família fez parte de um coletivo que vivia sua vida separadamente, mas unificado pelo laço social amarrado pela TV.

Tempos depois, o mesmo laço, como já comentado, volta num sentido dúbio. Não esquecemos o tempo em que o primeiro foi "atado". No presente, o reconstruímos com a interferência do passado e com as experiências.

Foram de 16 anos o intervalo entre a primeira exibição, na Rede Globo, e a reprise no Viva. A telenovela trouxe essa sensação de velocidade com o passar dos anos. Refletimos que as horas passam da mesma forma como antes, o que muda é noção do tempo que temos. 
Entretanto, após a análise desses dados, reafirmamos que há uma memória teleafetiva nos telespectadores de Laços de Família, sendo ela, aquela que é reformulada e recuperada por uma nova experiência ao rever na televisão, revisitando cenas de um tempo que trouxe pulsões com as recordações. 0 laço social foi reconstruído com as emoções e os afetos ao estarem novamente nesses espaços de reminiscências.

Esses "lugares" podem ser associados ao que Bergson (1999)², de acordo com Halbwachs (2003), chama de reconhecimento por imagens. Ao revisitar um local, mesmo que seja um programa de televisão, nossas recordações são ativadas por reconhecermos as imagens contidas nele. Os sentimentos que visualizamos nestas falas são recriados pelas associações e ligações que os telespectadores fazem ao "revisitar" a história.

\section{Considerações finais}

Com tamanha representatividade, a participação em rede do brasileiro permite olharmos desdobramentos sobre o consumo de televisão no país, os hábitos e expressões da audiência, frente a uma programação horizontal disponível.

Se na televisão aberta o impacto deste envolvimento do telespectador já desperta curiosidade, nos canais fechados, onde temos uma audiência mais restrita, peculiar e heterogênea, o interesse por investigações referentes a eles torna-se singular.

Confirmamos que, além das afetividades que cada telespectador manifesta, há uma teleafetividade que predomina e justifica a audiência do canal. Nos telespectadores do Canal Viva, isso ocorre porque há vibrações emocionais que vêm com a experiência televisiva. A TV é um "lugar" de revisitação, que faz voltar no tempo.

Este fenômeno pode ser explicado porque há um prazer em voltar ao passado com as imagens da televisão. Ela agrada porque traz novamente um laço social, reconstruído com as reminiscências e com as experiências coletivas e individuais atuais do sujeito. Possuímos memória afetiva desde pequenos. Somos formados por sentimentos, e as pessoas que estão ao nosso lado auxiliam nisso. Os grupos de referência interferem na aquisição dos sentimentos.

A TV consiste em um destes grupos, que, além de auxiliar na formação dos afetos, tem a possibilidade de atuar como objeto de evocação da memória. Por isso, a memória do

\footnotetext{
2 BERGSON, Henri. Matéria e memória: ensaio sobre a relação do corpo com o espírito. 2.ed. São Paulo: Martins Fontes, 1999. Apud Halbwachs (2003).
} 
telespectador não é somente afetiva e sim teleafetiva por conta da relação de uma experiência televisiva, que só ela é capaz de fazer.

Trata-se de um laço social que traz de volta o "estar com". As sensações nostálgicas descritas pelos internautas foram decisivas para concluir que o sujeito sempre recorda por intermédio de outras pessoas. A coletividade e a socialização são fatores que determinam a memória e os afetos.

A coletividade da memória contribui neste movimento. Lembremos que, mesmo individual, a memória é coletiva (HALBWACHS, 2003). Os grupos de referência atuam na formação de memórias. E isso constatamos nas lembranças e afetos expressos nos comentários de Laços de Família. Vimos a nostalgia, a saudade, a infância, a trilha sonora, as personagens, atores e atrizes, que repercutiram em rememorações de um tempo com a família, com os amigos, na escola ou trabalho. Todos, incluindo a TV, constatamos como sendo grupos de referência do indivíduo.

É pelo laço social reconstruído pelas reminiscências que visualizamos a teleafetividade das memórias. Um laço social que foi revisitado. A televisão socializa e colabora para a construção da memória. É por ela que, também, voltamos no tempo. Por exemplo: o indivíduo que assistiu Laços de Família no ano 2000 presenciou as personagens, o contexto narrativo, os atores e a trilha sonora. Naquele momento, um laço social invisível foi realizado em função da TV aberta, da coletividade e dos grupos de referências. A televisão e a telenovela também estavam presentes neste coletivo e fizeram parte do cotidiano, do momento com amigos, na escola ou universidade, no trabalho e no ambiente familiar desse sujeito. Situações particulares, ou não, ocorreram, na medida em que foi um tempo vivido por ele, que, ao (re)assistir, no Viva, a história, fez aquele laço social ser reconstruído, agora pelas recordações evocadas. Podemos dizer que a teia invisível que une as pessoas, descritas por Wolton (1996) através da televisão, é tão forte, que não se limita somente à "igualdade" de assistir uma programação, mas também traz marcações de momentos na vida de cada um.

A emoção e os afetos só ocorrem por conta desta socialização. Por isso, a comprovação de que só houve lembranças e sentimentos por este tempo passado, porque a televisão estava junto com o sujeito. Caso contrário, se não estivesse, não traria essas sensações. Gostamos da nostalgia porque estamos emocionalmente ligados ao mundo, e as emoções estão presentes em nossas memórias, de forma movente e também cristalizadora. 


\section{Referências}

BARDIN, Laurence. Análise de conteúdo. São Paulo: Edições 70, 2011.

BRESSAN JÚNIOR, Mario Abel. A memória afetiva e os telespectadores: um estudo do Canal Viva. 2017. Tese (Doutorado em Comunicação Social) - Programa de Pós-Graduação em Comunicação Social, Pontifícia Universidade Católica do Rio Grande do Sul, Porto Alegre, 2017.

BRESSAN JÚNIOR, Mario Abel. Um laço social revisitado na televisão: traços de uma memória teleafetiva. In: SEMINÁRIO INTERNACIONAL DE PESQUISAS EM MIDIATIZAÇÃO E PROCESSOS SOCIAIS, 2., 2018, São Leopoldo. Anais [...]. São Leopoldo: PPGCC Unisinos, 2018.

CAIXETA, Leonardo. Desenvolvimento histórico das neurociências das emoções. In: PÔRTO, Weyler Galvão (org.). Emoção e memória. São Paulo: Artes Médicas, 2006. cap. 1, p. 1-21.

FECHINE, Yvana. Elogio à programação: repensando a televisão que não desapareceu. In: CARLÓN, Mario; FECHINE, Yvana (org.). 0 fim da televisão. Rio de Janeiro: Confraria do Vento, 2014.

FERRÉS, Joan. Televisão subliminar: socializando através de comunicações despercebidas. Porto Alegre: Artmed, 1998.

FRAGOSO, Suely; RECUERO, Raquel; AMARAL, Adriana. Métodos de pesquisa para internet. Porto Alegre: Sulina, 2013.

HALBWACHS, Maurice. A memória coletiva. São Paulo: Centauro, 2003.

HUYSSEN, Andréas. Seduzidos pela memória: arquitetura, monumentos, mídia. Rio de Janeiro: Aeroplano, 2000.

IZQUIERDO, Ivan. Memória. 2. ed. Porto Alegre: Artmed, 2011.

LE BRETON, David. As paixões ordinárias: antropologia das emoções. Petrópolis: Vozes, 2009.

LOPES, Maria Immacolata Vassallo de; GRECO, Clarice. Brasil: a "TV transformada" na ficção televisiva brasileira. In: LOPES, Maria Immacolata Vassallo de; GÓMEZ, Guillermo Orozco (coord.). (Re)invenção de gêneros e formatos da ficção televisiva: anuário Obitel 2016. Porto Alegre: Sulina, 2016. p. 135-175.

POLLAK, Michael. Memória e identidade social. Estudos Históricos, Rio de Janeiro, v. 5, n. 10, p. 200-212, 1992.

SECCO, Duh. Exclusivo: segunda reprise de "Por Amor" no Viva lidera audiência da TV paga. [S.l.]: Terra, 24 maio 2017. 
WOLTON, Dominique. Elogio do grande público: uma crítica da televisão. São Paulo: Ática, 1996.

\title{
TV and revisit spaces: The formation of a tele-affective memory
}

\begin{abstract}
This study aims to analyze television as a space for social review for the viewers' formation of a tele-affective memory. It analyzes Canal Viva, which consists of a network composed by reruns. As an applied methodology, we use Laurence Bardin's Content Analysis, which establishes the research on the semantic meanings of viewers' comments published on Twitter. The results showed that, in addition to being affective, there is a tele-affective memory, resulting from the emotional effects of television, socialization and the affections built with reference groups. There is a pleasure in returning to the past by reconstituting a social bond with remembrances.
\end{abstract}

\section{Keywords}

TV. Tele-affective memory. Affective Memory. Social Media. Canal Viva.

Recebido em 19/05/2018

Aceito em 15/08/2018 